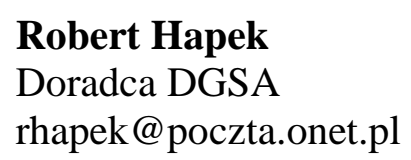

DOI: 10.35117/A_ENG_16_03_03

\title{
Labelling tank containers - a combination of letters and numbers or media relevant to the transport of dangerous goods information because "T6" does not always mean "instruction T6"
}

\begin{abstract}
This presentation is dedicated to the identification marking containers. Although her part refers to containers in general, the main emphasis is on marking tank-containers, including the carriage of dangerous goods. The presentation was discussed not only the system of coding - BIC CODE but also deciphered was the marking on the integrated plate (or individual plates). Discussed were also selected labeling elements operating in the ones that seem to look and sound quite mysterious. A large part of the presentation is devoted about a coding size and type of containers. In detail was discussed system complies with ISO 6346, taking into account changes, including the new one. On the end presentation we showed the differences on the labeling of the various modes of transport.
\end{abstract}

Keywords: Marking of containers; Transport of dangerous goods

With containers we meet virtually every day. The roads are full of trucks whose load are these magic boxes. Sometimes you can see a train carrying several containers, and sometimes the whole squad are just containers. The lucky ones can see ships loaded with containers, so much so that even obscure the ship. Although these "prosaic boxes" are so common , probably few people realize that their story is not so long.

The idea of a container is assigned an American transport company in Bowling Green LiftVan Company of New York, which already in 1906 started to use metal containers of fixed dimensions 18x8x8 inches, so small, for carrying small objects. The use of containers on a large scale began only in 1929 when it launched the transport by containers passengers' luggage from the Golden Arrow in relation London - Paris. The forerunner of the modern container transport is Malcom McLean, who in 1937 watched the process of transshipment of goods from ships to trucks and vice versa, he concluded that the wooden boxes of random size slows down the process of reloading. It's him who is considered to be the father of containerization. Mc Lean invented container and not only he understood what potential they provide in the form of cost reduction, productivity growth. He did but something much more important, namely, introduced this idea into force and through faster and better organized transhipment operations lowered the cost of 5.86 dollar to 16 cents per tonne. Container transport in today's form began only on 26 March 1956 when the first 58-foot container 35 set off to route from New York to Houston ship "Ideal X".

Regardless of the situation in which we see the container there is no need to be watchful to see that on each container - especially on the door or bottom borders - teeming consisting of letters and numbers subtitles. It is worth considering whether these letters and numbers, beyond the obvious information e.g. with a maximum permissible weight of the container, have any significance.

Identification of container, because that's the name of this combination of letters and numbers, consists of:

- identification marks - BIC code;

- code size and type;

- integrated labels or individual labels;

In order to highlight the importance of letters and numbers for the transport of containers, tanks, we will discuss this in a slightly different order. We will start from the plate. 
For each container is placed one or more plates marked with the variety of information whose purpose is to provide basic data on the producer, user, research and approvals. By far the most common is now integrated plate that in order to improve the legibility of the information supersedes all plates with one. Integrated plate includes plates:

- custom;

- informative (the manufacturer);

- CSC;

- ACEP.

Customs plate confirms that the container has been approved for transport under customs seal - it means the inability to gain access to the load without breaking the customs seal. This plate contains:

- custom code;

- approval number;

- manufacturer code and serial number.

Information plate contains the data of the owner, manufacturer and any other approvals e.g. admission of impregnation agent wooden parts of the container (a requirement of the Australian health department).Plate CSC confirms compliance the container with the requirements of the CSC Convention and contains:

- approval number (country of recognition, data recognition certificate);

- container manufacturing date (month and year);

- identification number the manufacturer;

- the maximum weight of a freight container ( $\mathrm{kg}$ or $\mathrm{lbs}$ );

- permissible weight of the damming at $1.8 \mathrm{~g}$ (kg or lbs) - $1.8 \mathrm{~g}$ describes the vertical acceleration forces in relation to the acceleration of gravity (obtained by uniform loading of $1.8 \times$ max gross weight);

- allowable load in testing lateral deformation (kg or lbs) -ranking tests.

ACEP Plate (approved continuous examination program) confirms that the container has an approved program of permanent technical supervision (new containers do not need to be checked for the first five years after production, after this period, the containers must be inspected at least once every 30 months. ACEP Plate contains:

- acronym ACEP;

- country of program approval;

- the approval number of the program;

- year of program approval;

- letter abbreviation of the owner (at his request).

Placed on the container operational labeling is to inform not only the parameters of the container, equipment and how to use it but also warning of the dangers that may arise when performing maintenance. Information on the basic parameters of container in order to allow proper reading are given in both metric and Anglo-Saxon and concern:

- permissible total weight;

- own weight;

- permissible load;

- the volume of cargo space;

- capacity.

In contrast to those presented in the form of digital data on key parameters, information about equipment, use of equipment, and warning of the dangers are presented in the form of pictograms. The most commonly used pictograms, which can be seen on the walls of the containers are, for example.:

- a sign indicating that the height of the container is greater than $2.6 \mathrm{~m}$;

- sign indicating the prohibition of lifting a loaded container by dolly; 
- sign warning against the danger of electric shock from the catenary (in case of containers equipped with ladders);

- sign indicating the prohibition of transporting by dolly.

Containers bear the mark consisting of letters, numbers or their combination. This marking indicates of approvals which container has or confirming compliance with the relevant requirements. Not only that, sometimes there are a lot of signs and they sound quite mysterious. Let's look.

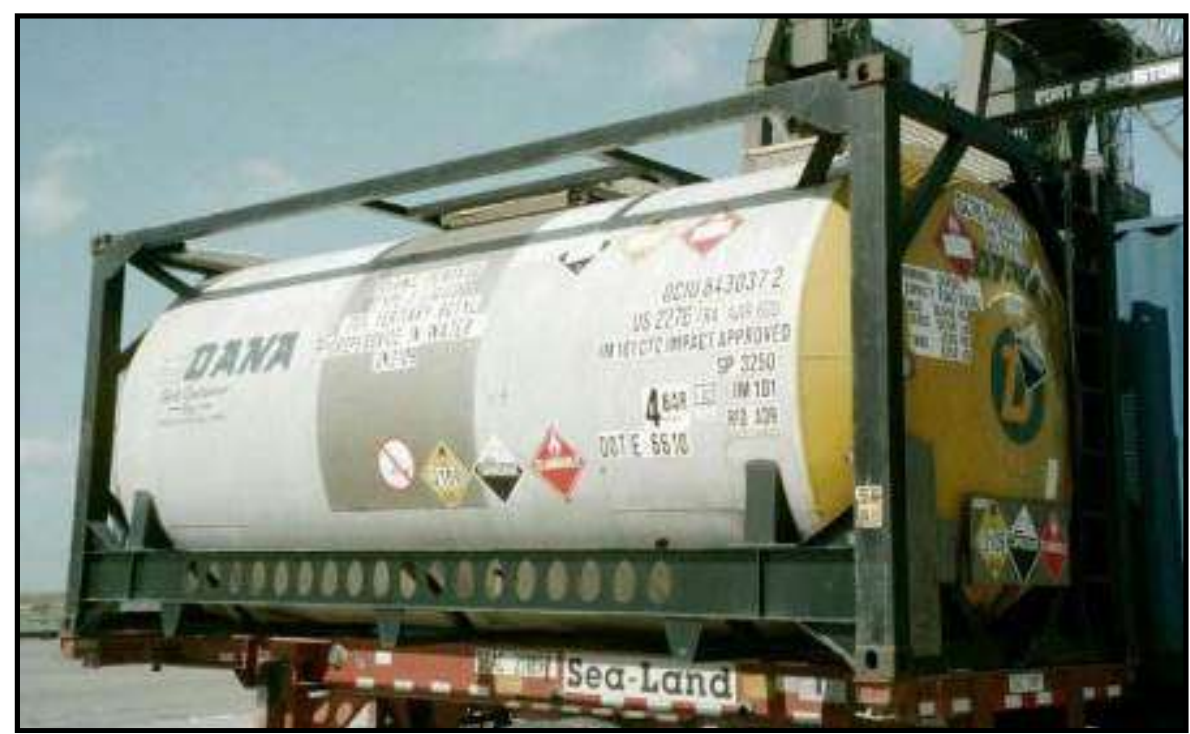

Markings "RID-ADR" you do not need explanation. One problem may be with the "IM 101" but this is only a minor inconvenience, because even knowing the meaning you can guess that it is a "IMO 1". And what mean "CTC IMPACT APPROVED", "DOT E 6610", "AAR 600", "IC 70". It is true that they sound mysteriously. They mean, respectively: admission to operation on Canadian railways (Canadian Transport Commission), the confirmation of the company ARCO Chemical (E 6610) of fulfilling Code of Federal Regulations requirements or standard shipments of dangerous goods within the United States and the 48 states of the continental US to Canada (CFR49) - the latter two information are hidden in the letters "DOT" admission to operation on the US railway (American Association of Railroads), the confirmation the compliance of the container with the requirements of the International Union of Railways (UIC) - "70" number of the country in accordance with the numbering UIC.

On the container we can also see an in-line string of four letters and seven digits, of which the last is placed in the frame. This magic string is code BIC (Bureau International des Containers et du Transport Intermodal). This code includes:

- owners' code (3 letters);

- categories of equipment identifier (1 letter);

- the serial number of the container (6 digits);

- check digit (1 digit).

Let us move to a much more interesting, informing about the size and type (a simpler purpose) container element container labeling. To the size and type of code, which, depending on the age of the container consist of two letters and four numbers indicate respectively:

- country of registration code (2 letters);

- size code (2 digits);

- type code (2 digits).

or include a four-element combination of letters and numbers whose meaning is as follows:

- size code (2 signs);

- type code (2 signs). 
The first type is compatible with ISO 6346 (1985) and is still acceptable to use - there is no requirement for recoding so labeled containers. Let's see what is the significance of individual numbers:

- first determines the length of container;

- the second defines the height of container;

- the third specifies the type of container;

- fourth feature of the type.

The present system is very simple and does not cause problems of interpretation. Each number has a very specific meaning. The greatest practical importance, however, have the last, fourth digit indicating the performance properties of the container. To see this we need to look at the full development of this group of markings, which in the case of tank containers is as follows:

\begin{tabular}{|c|l|l|l|}
\hline \multirow{4}{*}{7} & 0 & Ciecze bezpieczne, ciśnienie maksymalne 0,45 bar \\
\cline { 3 - 4 } & & 1 & Ciecze bezpieczne, ciśnienie maksymalne 1,5 bar \\
\cline { 3 - 4 } $\begin{array}{l}\text { Kontener } \\
\text { zbiornikowy } \\
\text { (tank container) }\end{array}$ & 2 & Ciecze bezpieczne, ciśnienie maksymalne 2,65 bar \\
\cline { 3 - 4 } & 3 & Ciecze niebezpieczne, ciśnienie maksymalne 1,5 bar \\
\cline { 3 - 4 } & 4 & Ciecze niebezpieczne, ciśnienie maksymalne 2,65 bar \\
\cline { 3 - 4 } & 5 & Ciecze niebezpieczne, ciśnienie maksymalne 4,0 bar \\
\cline { 3 - 4 } & 6 & Ciecze niebezpieczne, ciśnienie maksymalne 6,0 bar \\
\cline { 3 - 4 } & 7 & Ciecze niebezpieczne, ciśnienie maksymalne 10,5 bar \\
\cline { 3 - 4 } & 8 & Ciecze niebezpieczne, ciśnienie maksymalne 22,0 bar \\
\hline
\end{tabular}

Discussed the scheme covered only containers in the strict sense, and has been changed. A new one also includes a swap body and there are used in the nomenclature codes of groups and encoding size and type, to increase the flexibility of the system, are used for both letters and numbers. This system for containers - tanks may be the reason for quite a considerable problem. Why? Because a literal compliance between the type code and numbering ofportable tank instruction. Here's the proof.

\begin{tabular}{|c|c|c|c|c|}
\hline $\begin{array}{l}\text { KO } \\
\text { D }\end{array}$ & $\begin{array}{l}\text { KOD } \\
\text { GRUPY }\end{array}$ & TYP & KOD TYPU & GŁÓWNA CECHA \\
\hline \multirow{10}{*}{$\mathrm{T}$} & \multirow{3}{*}{$\mathrm{TN}$} & \multirow{3}{*}{$\begin{array}{ll}\text { Kontener cysterna dla } \\
\text { cieczy innych niż } \\
\text { niebezpieczne }\end{array}$} & T0 & Minimalne ciśnienie 0,45 bar \\
\hline & & & T1 & Minimalne ciśnienie 1,5 bar \\
\hline & & & $\mathrm{T} 2$ & Minimalne ciśnienie 2,65 bar \\
\hline & \multirow{4}{*}{ TD } & \multirow{4}{*}{$\begin{array}{l}\text { Kontener cysterna dla } \\
\text { cieczy innych } \\
\text { niebezpiecznych }\end{array}$} & T3 & Minimalne ciśnienie 1,5 bar \\
\hline & & & $\mathrm{T} 4$ & Minimalne ciśnienie $2,65 \mathrm{bar}$ \\
\hline & & & T5 & Minimalne ciśnienie 4,0 bar \\
\hline & & & T6 & Minimalne ciśnienie 6,0 bar \\
\hline & \multirow{3}{*}{ TG } & \multirow{3}{*}{$\begin{array}{l}\text { Kontener cysterna dla } \\
\text { gazów }\end{array}$} & $\mathrm{T} 7$ & Minimalne ciśnienie 10,5 bar \\
\hline & & & $\mathrm{T} 8$ & Minimalne ciśnienie 22,0 bar \\
\hline & & & T9 & Jeszcze nieokreślone \\
\hline
\end{tabular}

So far, these problems are not visible? Let see how this marking looks on the tank. 


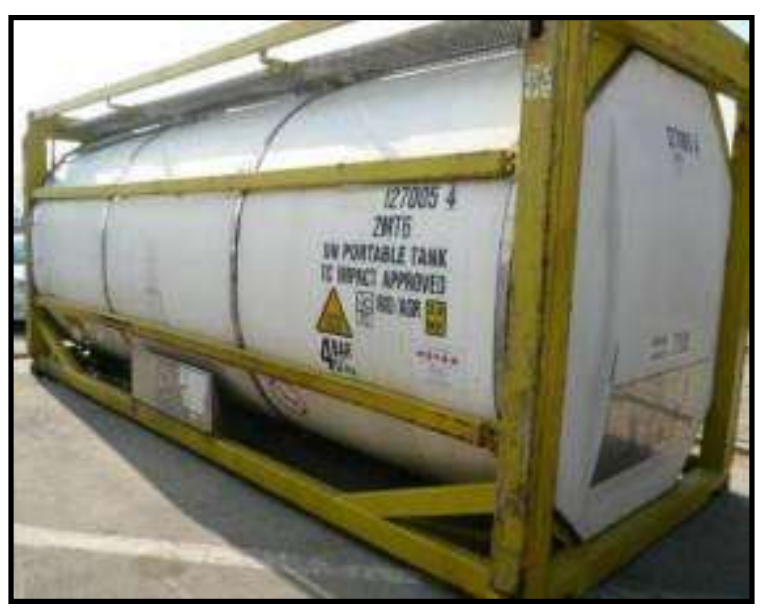

And what can we see? We see that we are dealing with a portable tank - as evidenced by the inscription "UN PORTABLE TANK". But which portable tank instruction is assigned to the tank? Unfortunately you can not categorically say that this is a statement T6, and so can accept someone to whom coding system is a stranger. Lack of knowledge in this field can be the substrate for very serious problems, and not just during the inspection. What worse it can cause a great threat if the goods will be loaded into the wrong tank.

Indicated above inconvenience coding system in a very simple manner may be removed. Just ask yourself the minimum effort and affix on the tank signage informing about appropriate tank instruction for the portable tank. So labeled tank looks like this.
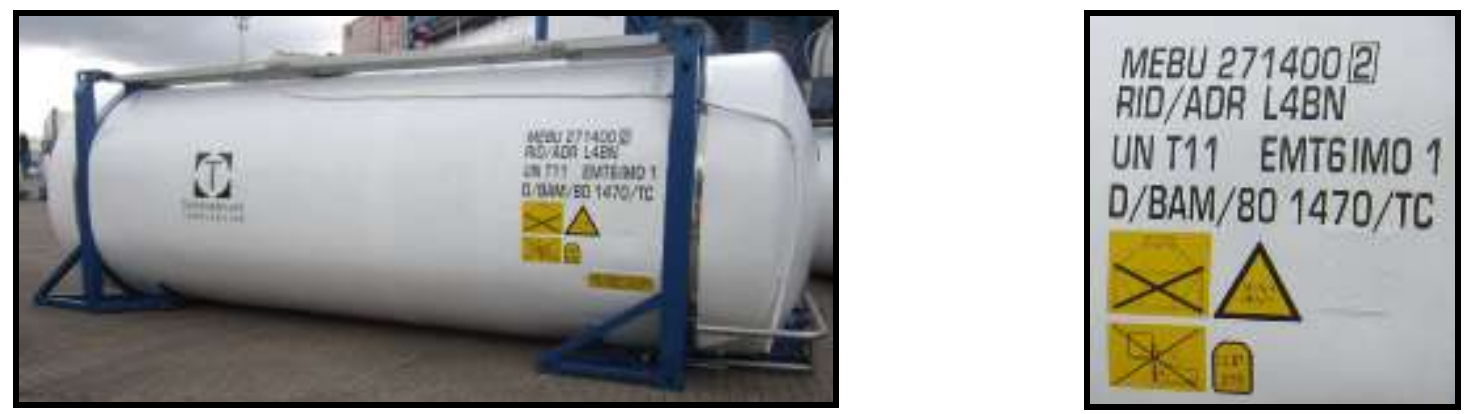

Seemingly everything is clear - we see the code (22T6) and the instructions in the portable tank (T12). But before committing an error protects, unfortunately, knowledge of the meaning of each component of the label.

To completely eliminate the described disadvantage the coding system has been modified. The new system, although assuming more flexible, can sometimes be difficult for the user. Why? The letter " $\mathrm{T}$ " was replaced to the letter " $\mathrm{K}$ " and it was introduced additional information about the ability of the container to damming. To achieve this for containers with unlimited damming left digits, and for containers with limited damming the letter were added. In addition, labeling for tank containers was significantly expanded previously encrypted with a code T6. The use of letters and numbers, including their combinations, to describe the size and type of container requires from the user much more knowledge. For proof, let's look at the signs of two identical-looking containers. 

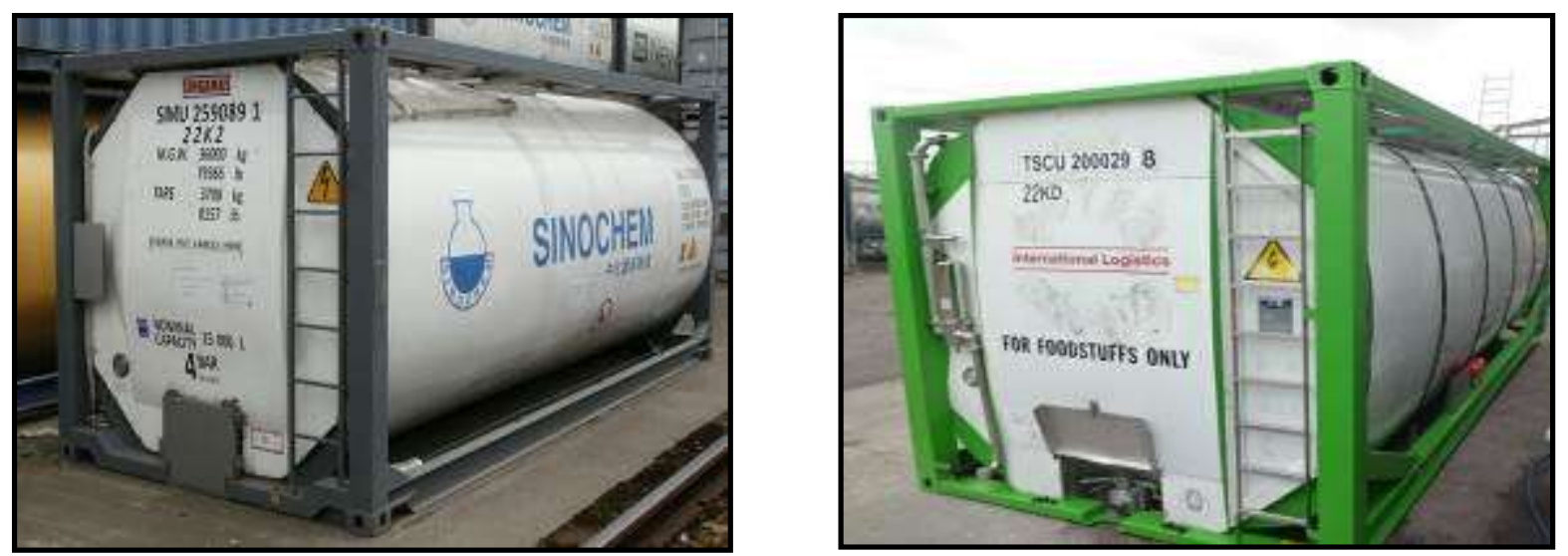

Presented containers have the same size (the number "22") and the same pressure ("K"), but a totally different capacity of damming. Right unlimited (the number "2"), and the left limited ("D"). So we have the first evidence for a much greater need for knowledge that is required for proper operation of the container. Here's the second.

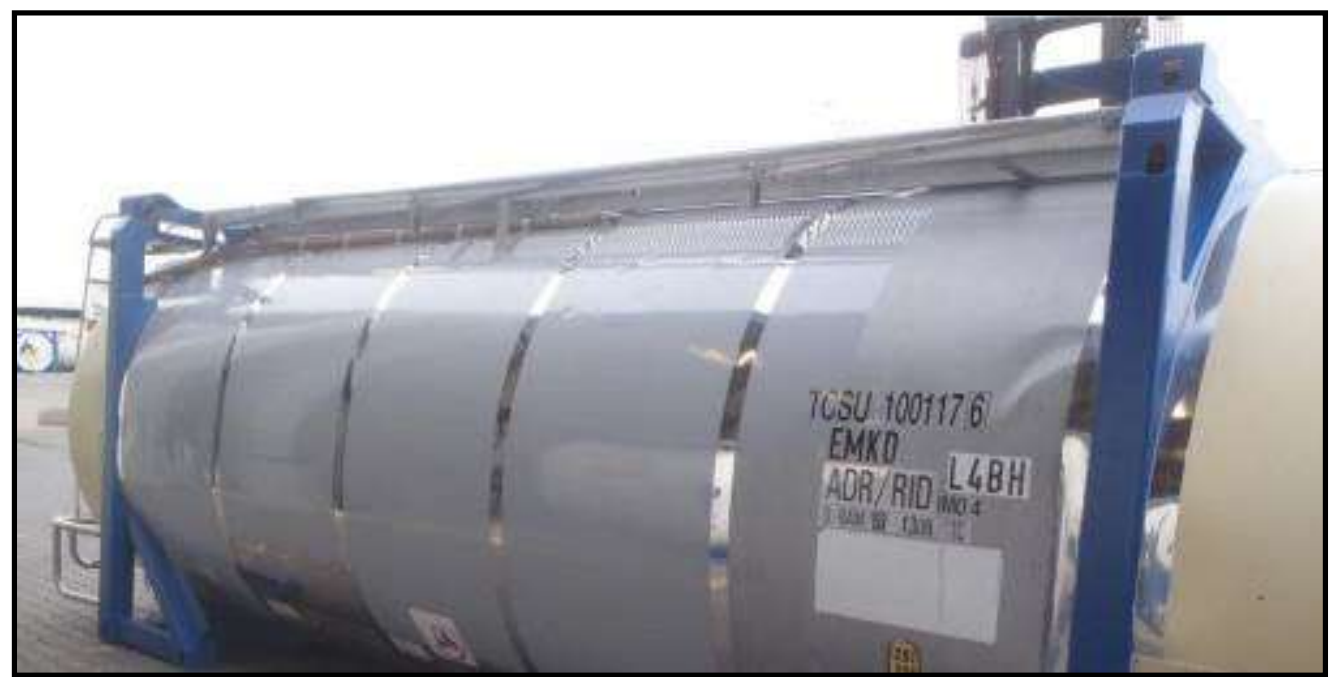

Although the new system of tank containers, is the third modification of the encoding does not mean that operated containers must be transcoded. Of course, nothing stands in the way to do it. However, the lack of extreme caution may end up with a total disinformation. Why? That is why.
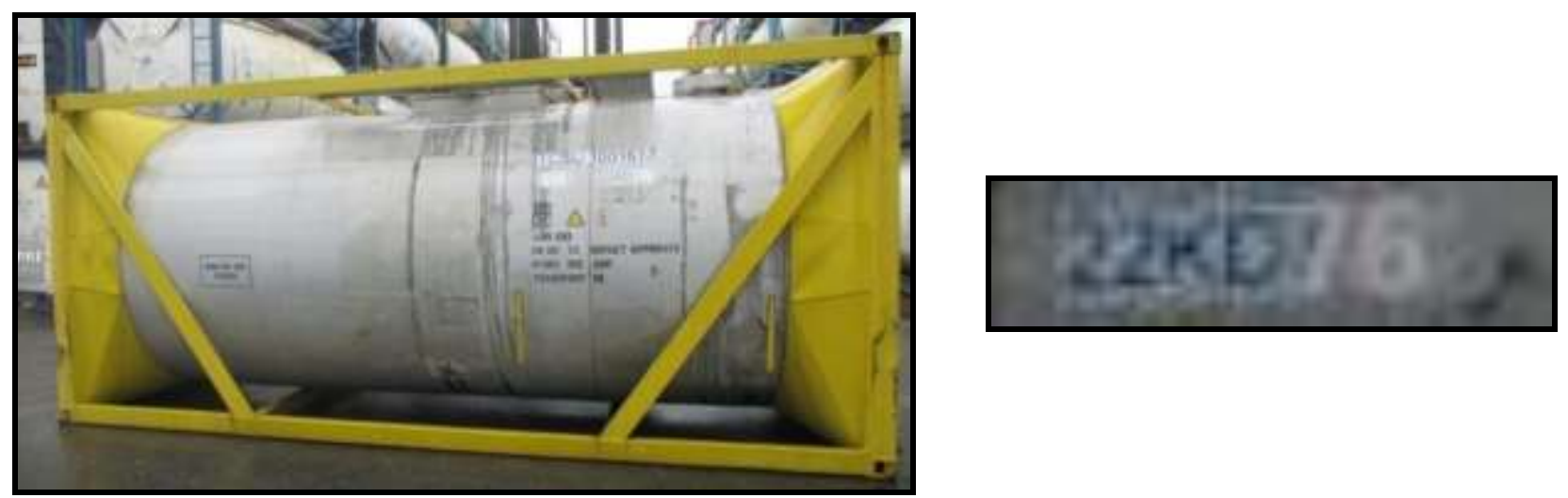

We see the combination of the oldest and the newest coding system. In the context of provided information raises the obvious question. Will a user with only a superficial knowledge about the coding system be able to properly operate such a marked container. It is highly doubtful. Such a recoding of the container is therefore dangerous. On the surface, it seems not. Nothing could be 
further from the truth. The letters "KD" in the code indicate that we are dealing with a container with pressure min 6 bar with a limited ability to impoundments and the numbers "76" indicate only a pressure of 6 bar. Therefore, regardless of whether the code will be read "22KD," "KD76" or "2276" it is still the lack of a thorough knowledge, that risk making a mistake.

Labelling tank containers carrying dangerous goods are not only discussed above, coding and marking. It also marking required under relevant to a particular mode of transport. In this case, it is also required highly specialized knowledge, because sometimes the differences are very small. A good example is the attention to the chapter 5.3.7 SMGS, which is exempt from the obligation to affix the card number of emergency the territory of some states. Similarly, great attention should be paid to use of labels with the number of cards emergency. According to ADR and RID labels may have subtitles, the text should be limited to a description of the type of risk and precautions while handling the art of shipment. Can therefore label on the container tank have emergency card number? Someone with only a superficial knowledge finds it has. Unfortunately it's a mistake, because the provisions of the ADR and RID for the application of labels containers, tanks say that labels are conform to the provisions not only in terms of design but also additional subtitles. Similar examples can be found more. Though other proper shipping names for certain goods. Situations do not change contained in the legislation provisions permitting, of course, under certain conditions, to transport the consignment marked in accordance with the requirements of other provisions. As a result, consignments by different modes of transport after reaching the destination are mostly marked with signs specific to each type of transport.

Taking into account that the containers, including tank containers, as transport equipment are quite durable changed several times coding system leads to a situation in which the users need more expert knowledge. 